\title{
PSEUDOPTERÍGIO EM COELHO-ANÃO (ORYCTOLAGUS CUNICULUS): RELATO DE CASO
}

\author{
(Pseudopterygium in a dwarf-rabbit (Oryctolagus cuniculus): case report)
}

\author{
André Saldanha ${ }^{1}$, Mariza Bortolini ${ }^{1}$, Nathália Mendonça de Seabra ${ }^{1}$, Adrien Wilhelm Dilger \\ Sanches ${ }^{1}$, Rogerio Ribas Lange ${ }^{1}$, José Ricardo Pachaly ${ }^{2}$, Fabiano Montiani-Ferreira ${ }^{1}$ \\ ${ }^{1}$ Universidade Federal do Paraná, ${ }^{2}$ Universidade Paranaense. \\ *Correspondência: saldanha255@gmail.com
}

RESUMO: Uma fêmea de coelho-anão apresentando uma membrana vascularizada exuberante cobrindo cerca de $90 \%$ da superfície corneana do olho direito foi atendida em um hospital veterinário universitário. Com diagnóstico de pseudopterígio, a coelha foi submetida a intervenção cirúrgica corretiva, com técnica baseada em incisão da conjuntiva aberrante em três secções radiais. $O$ tecido restante foi suturado à conjuntiva bulbar com fio absorvível poliglactina 910 de calibre 6-0, empregando-se ciclosporina tópica para prevenção de recidivas. Ao exame histopatológico o tecido apresentava estroma conjuntivo normal revestido por epitélio conjuntival, sem células caliciformes. $O$ animal se recuperou sem intercorrências e nenhum sinal de recidiva foi observado trinta dias após o procedimento.

Palavras-chave: lagomorfo; oftalmologia; membrana aberrante; pseudopterígio

\begin{abstract}
A female dwarf-rabbit presenting an exuberant vascularized membrane covering about $90 \%$ of the corneal surface of the right eye was examined and treated at a veterinary teaching hospital. Diagnosed with pseudopterygium, the animal was submitted to corrective surgery based on incision of the membrane in three radial sections. The remaining tissue was sutured to the bulbar conjunctiva with 6-0 polyglactin 910 . Topical cyclosporine treatment was prescribed to avoid recurrences. Histopathological analysis showed normal stroma and conjunctival epithelium with no goblet cells. The rabbit recovered with no complications and no signs of recurrences were noticed until thirty days after surgery.
\end{abstract}

Key Words: lagomorph; ophthalmology; aberrant membrane; pseudopterygium 
INTRODUÇÃO

O emprego de pequenos mamíferos como animais de estimação tem aumentado nas residências brasileiras, e da mesma forma aumenta a casuística de atendimento desses pacientes nos estabelecimentos veterinários. No Setor de Medicina Zoológica do Hospital Veterinário da Universidade Federal do Paraná (HVUFPR, Curitiba, Paraná, Brasil), a maior casuística de animais exóticos de estimação se refere a coelhos. São atendidos principalmente casos odontológicos, digestivos e ortopédicos, observando-se também outras afecções, como problemas oncológicas e oftalmológicos.

A ciência oftalmológica aplicada aos coelhos necessita de aprofundamento, quando comparada à canina. Williams (2012) relata de forma preliminar que $26 \%$ da população de lagomorfos do Reino Unido apresenta alterações oculares, sendo que 17\% desses animais têm algum grau de opacificação corneana, 3,5\% apresentam dacriocistite e $2,5 \%$ apresentam lesões corneanas.

O crescimento conjuntival aberrante é um quadro incomum, com ocorrência exclusiva em coelhos, e ainda pouco descrito na literatura científica (Turner, 2008). Caracteriza-se pelo crescimento progressivo rápido da conjuntiva a partir do fórnice conjuntival, ocasionando a formação de um anel que pode cobrir a superfície da córnea de forma completa ou parcial. Normalmente não se observa quadro clínico associado à sua presença, pois conjuntiva bulbar e palpebral não apresentam sinais significativos de inflamação. Ainda assim, é comum observar desconforto, alteração de comportamento e certo nível de déficit visual. A causa do crescimento conjuntival aberrante em coelhos ainda é completamente desconhecida, sendo aventadas as hipóteses de problemas imunomediados, inflamatóriod e traumáticos (Roze et al., 2001; Allgoewer et al., 2008; Katsuta at al, 2008; Kim et al., 2013). Ocorre de forma unilateral e bilateral, com incidência predominantemente em coelhos-anões, sem predileção por sexo e/ou idade.

O tratamento cirúrgico é indicado para evitar lesões corneanas, dar conforto ao paciente e melhorar a qualidade visual, porém as recidivas são frequentes (Turner, 2008). As abordagens cirúrgicas descritas na literatura incluem remoção radical da conjuntiva que se estende sobre a córnea, em diferentes padrões de incisão radial e de sutura (Arnbjerg, 1979; Schoofs, 1998; Allgoewer et al., 2008; Williams, 2012; Kim et al., 2013). Relata-se aqui uma intervenção cirúrgica aprimorada aplicada a um quadro de crescimento conjuntival aberrante em uma fêmea de coelhoanão com idade de sete meses.

\section{MATERIAL E METODOS}

Uma fêmea de coelho-anão (Oryctolagus cuniculus) de sete meses foi atendida no Setor de Medicina Zoológica do HV-UFPR, em função da queixa de alteração ocular no olho direito, inquietação e agressividade. Foi relatado crescimento progressivo de uma membrana sobre o olho direito, a partir do canto medial com evolução de aproximadamente dois meses, sem outras alterações sistêmicas ou oftálmicas dignas de nota.

Ao exame físico a paciente se apresentava alerta, ativa, responsiva e com boa condição corporal. Ao exame de biomicroscopia com lâmpada de fenda (Hawk Eye, Dioptrix, L'Union, France), foi notada uma membrana esbranquiçada, vascularizada e delgada 
ocupando aproximadamente $90 \%$ da superfície corneana do olho direito, ficando descoberta de forma centrífuga somente uma área axial (Figura 1). Não foram observados sinais de inflamação, secreção, prurido, lacrimejamento ou blefaroespasmo, ou alterações referentes às estruturas intraoculares. 0 teste de ofuscamento teve resultado normal, e nenhum déficit visual foi notado. Diante das características da lesão e da ausência de outras alterações, foi diagnosticado crescimento conjuntival aberrante unilateral e indicado tratamento cirúrgico. Exames laboratoriais préoperatórios de rotina não evidenciaram nenhuma alteração, e a paciente recebeu como medicação préanestésica, por via intramuscular, a combinação de butorfanol $(0,5 \mathrm{mg} / \mathrm{kg})$, midazolam $\quad(1,0 \quad \mathrm{mg} / \mathrm{kg}) \quad \mathrm{e}$ dexmedetomidina $(40 \mu \mathrm{g} / \mathrm{kg})$. A seguir foi entubada com sonda endotraqueal 2.0 para indução e manutenção com isoflurano. Além disso, foi realizado bloqueio intraconal com lidocaína a $2 \%$ sem vasoconstritor $(0,1 \mathrm{~mL} / \mathrm{kg})$. A região periocular foi depilada, e a seguir degermada com solução de iodopovidona.

Após realização de cantotomia lateral, o bulbo ocular foi posicionado com blefarostato. Constatou-se que a conjuntiva aberrante não estava aderida a nenhum ponto da córnea, sendo possível sua manipulação sem necessidade de realizar ceratoplastia lamelar. Com o auxílio de um microscópio cirúrgico (DFV MU-M19, Rio de Janeiro, Brasil) e empregando tesoura de Westcott, foram realizadas incisões parciais sobre o crescimento conjuntival em três locais, radialmente, do centro da córnea ao limbo. Cada secção da conjuntiva foi incisada até o limbo, afastando assim todo o excesso de tecido conjuntival que se sobrepunha à córnea.

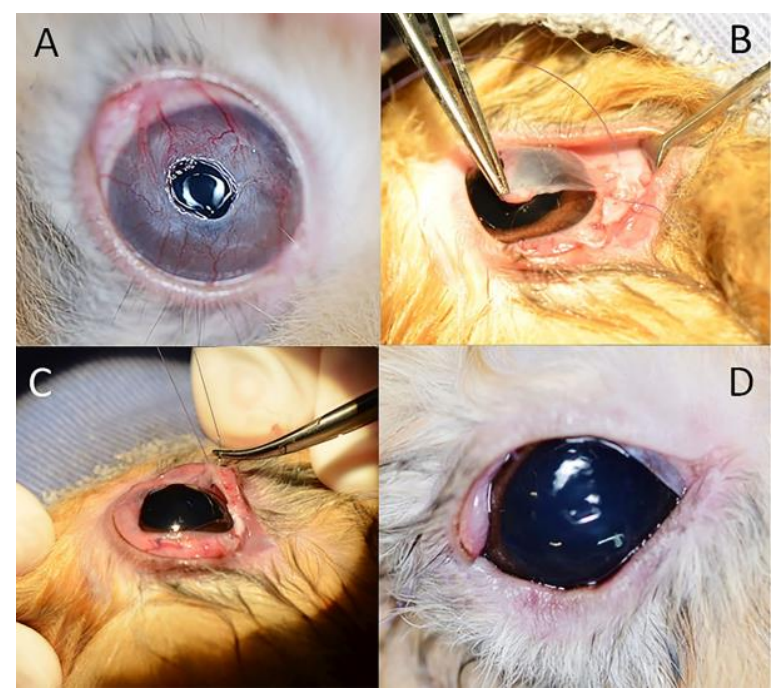

Figura 1 - $(\mathrm{A})$ Membrana superficial vascularizada sobre a córnea com seu caráter centrípeto, permitindo visualização direta da córnea apenas em região axial. (B) Três incisões radiais foram realizadas da margem livre da membrana até o limbo, separando-as em três porções. É possível observar que a membrana não estava aderida à córnea, não sendo necessária a realização de ceratoplastia. C: Após excisão da membrana aberrante, foi realizada sutura em padrão Lembert da membrana remanescente sobre a conjuntiva bulbar. D: Resultado final logo após a cirurgia, observando-se ausência de qualquer tecido recobrindo a córnea e pontos na pele, exceto na cantorrafia.

Cada secção da conjuntiva foi incisada até o limbo, afastando assim todo o excesso de tecido conjuntival que se sobrepunha à córnea. Suas bordas foram então refletidas e suturadas nas margens externas de incisões arciformes criadas na conjuntiva bulbar, com fio de poliglactina 910 calibre $6-0$ em padrão interrompido de Lembert (Figuras 1 e 2). A cantorrafia lateral foi realizada com sutura simples interrompida utilizando poliglactina 910 6-0.

Amostras do tecido conjuntival foram colhidas, fixadas em formol a $10 \%$, embebidas em parafina, cortadas em seções de $5 \mu \mathrm{m}$ e coradas com hematoxilina-eosina para avaliação microscópica. 


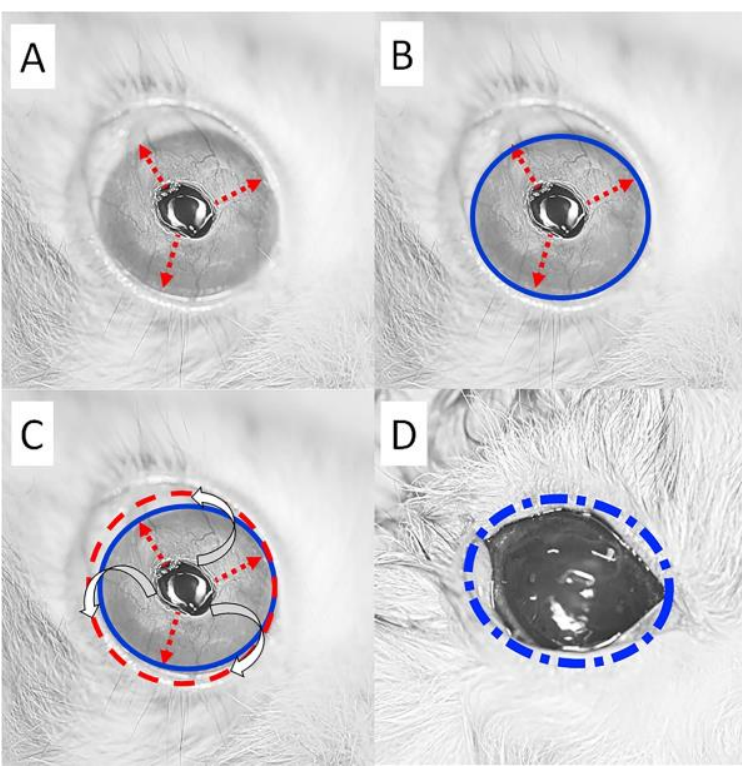

Figura 2 - (A) Incisão radial realizada em três pontos, partindo da margem livre da membrana na região axial da córnea até o limbo (setas pontilhadas vermelhas). (B). As três abas de tecido aberrante resultantes foram refletidas (dobradas) logo imediatamente após o limbo (círculo azul). (C) Indicação do local de realização da sutura em padrão Lembert na margem distal da conjuntiva bulbar, após a realização de incisão (círculo vermelho, 2-3 mm do limbo) em toda extensão circular. (D) Resultado final, sem tecido conjuntivo sobre a córnea e sutura mantida na conjuntiva bulbar sem incluir a pálpebra.

Durante o período transoperatório não foi observada nenhuma complicação e a recuperação anestésica não teve intercorrências. No período pós-operatório foi usado continuamente um colar elisabetano, e o olho operado foi medicado a cada 12 horas com colírio de dexametasona (1 $\mathrm{mg} / \mathrm{mL})+$ neomicina $(5 \mathrm{mg} / \mathrm{mL})+$ polimixina $B(6000 \mathrm{Ul} / \mathrm{ml})$ por 30 dias, e pomada oftálmica de ciclosporina a $1 \%$ (uso contínuo a cada 12 horas).

Oito dias após o procedimento, foram observados sinais de fibrose na área de sutura da conjuntiva bulbar suturada. Não havia sinais de hiperemia e edema da conjuntiva, mas um dos pontos de sutura havia se soltado. Como a região suturada já apresentava tecido cicatricial, se optou pela remoção daquele ponto, sendo mantidos os demais. A deiscência ocasionou uma área de atrito, resultando em uma úlcera corneana superficial localizada na posição de 12 horas, demandando prescrição do uso de colírio de tobramicina e gel oftálmico de dexpantenol, ambos aplicados a cada oito horas, durante sete dias. A paciente foi reavaliada 14 dias após a intervenção, quando apresentou a úlcera de córnea já solucionada, e fibrose na região de sutura da conjuntiva. Trinta dias após o procedimento cirúrgico, não foram observadas evidências de recidiva.

\section{RESULTADOS E DISCUSSÃO}

O crescimento conjuntival aberrante em coelhos foi primeiramente relatado por Arnbjerg (1979) em um coelho-pigmeu

(Brachylagus idahoensis), sendo também descrito em coelhos-anões (Oryctolagus cuniculus) (Allgower et al., 2008; Kim et al., 2013), Rex (Fisher, 2002) e Nova Zelândia (Katsuta et al., 2008). Esse quadro costuma ser denominado na literatura como pseudopterígio na literatura, mas tal conceito difere da condição de pterígio que ocorre em pessoas, em que a lesão é caracterizada como um crescimento de conjuntiva em direção a um defeito anterior ocasionado na córnea, de modo a aderir à mesma (Roze et al., 2001). Já nos lagormorfos, se observa tecido conjuntival de crescimento extensivo sobre a superfície da córnea, sem, no entanto, aderir à mesma (Roze at al 2001), e geralmente não é relatada a presença de uma lesão prévia na córnea.

Katsuta et al. (2008) sugerem que em coelhos, tal condição seja definida como pseudopterígio, da mesma forma que em pessoas, considerando que as diferenças na apresentação da lesão, como não aderência e/ou alteração na córnea e crescimento concêntrico, são meramente fatores interespecíficos. Fatores inflamatórios e/ou traumáticos 
podem ser predisponentes para 0 crescimento conjuntival, já que a causa dessa condição em coelhos ainda é desconhecida. Entre as possíveis causas aventadas encontram-se traumatismos, condições inflamatórias, displasia de colágeno e fatores imunomediados (Allgoewer et al., 2008; Kim, et al., 2013; Roze et al., 2001; Katsuta et al., 2008). Liberge et al. (1999) descreveu a ocorrência de crescimento conjuntival aberrante em oito de 60 coelhos submetidos a testes laboratoriais intraoculares por um ano, porém com ocorrência pouco consistente, ou seja, em ambos os olhos tratados e não tratados, uni e bilateralmente. Apesar da grande frequência do uso de coelhos em experimentos oftalmológicos, esse é o único relato publicado em referência a animais de laboratório. $\mathrm{Na}$ anamnese do caso aqui apresentado, não foi notado nenhum desses prováveis fatores predisponentes.

Uma vez diagnosticado o crescimento de conjuntiva, o tratamento de eleição é cirúrgico. Apesar da condição não ser grave, pode causar comprometimento parcial da visão e desconforto crônico. Há descrição de tratamentos cirúrgicos bem-sucedidos, muitos deles, porém, com recidivas em períodos de poucas semanas (Williams, 2012; Kim et al., 2013; Roze et al., 2001; Arnbjerg, 1979). Holmberg (2008) descreve uma "técnica de Arlt modificada", na qual o tecido conjuntivo é seccionado ao meio horizontalmente e os bordos são suturados no fórnice conjuntival. Já Williams (2012) reforça que a simples ressecção da conjuntiva resulta em rápido crescimento redicivante, e que o uso de ciclosporina tópica pode adiar esse processo. 0 mesmo autor, entretanto, acredita que uma intervenção de cunho permanente seria a incisão radial da membrana e a sutura das extremidades na episclera. $\begin{array}{cccr}\text { O uso de } & \text { fármacos } \\ \text { imunomoduladores, } & & \text { como a }\end{array}$ ciclosporina, é sugerido para controlar recidivas. No caso tratado somente com antibioticoterapia local por Arnbjerg (1979), a recidiva ocorreu em algumas semanas. Roze (2002) estudou quatro indivíduos nos quais as membranas foram removidas cirurgicamente, e somete dois foram tratados com ciclosporina tópica. O retorno do crescimento conjuntival nos animais que não receberam esse tratamento ocorreu em dois meses, enquanto que os animais tratados com ciclosporina apresentavam crescimento mínimo um ano após o procedimento cirúrgico.

A técnica empregada no caso aqui relatado foi baseada na descrição de Kim et al. (2013), por sua vez baseada na proposta de Turner (2008). Kim et al. (2013) relatam dificuldades na aplicação da técnica citada Allgoewer et al. (2008), trabalhando com seis secções radiais, já que Turner (2008) sugere uma única linha incisional, o que dificulta a eversão da conjuntiva para sutura na conjuntiva bulbar. No caso em tela, utilizamos apenas três incisões radiais, originando porções maiores, de modo similar à técnica descrita por Schoofs (1998), que optou por segmentar a membrana em quatro partes, aliviando a tensão das bordas de incisão para sutura e permitindo manipulação mais ágil e prática. A secção radical do tecido e a sutura de Lembert foram utilizadas na intervenção, e no período pós-operatório prescreveu-se pomada de ciclosporina para evitar recidivas, como discutido anteriormente.

Ao exame microscópico, o tecido colhido era composto por estroma conjuntivo normal revestido por epitélio conjuntival, sem células calificiformes. Notou-se discreto edema estromal focal, congestão vascular e células inflamatórias - neutrófilos (Figura 3). Esses achados microscópicos condizem 
com o citado por Roze et al. (2001) e Allgower et al. (2008). Roze et al. (2001) descreveram a histopatologia do tecido de crescimento conjuntival de quatro animais como um epitélio conjuntival normal com presença de células mucóides, fibrócitos cercados por feixes de colágeno na lâmina própria e áreas com infiltrado inflamatório contendo neutrófilos, linfócitos e plasmócitos. A descrição histopatológica da uma única amostra analisada por Allgower et al. (2008) cita um epitélio escamoso sem células mucóides e 0 subepitélio neovascularizado, sugerindo também excesso focal de colágeno conjuntivo.

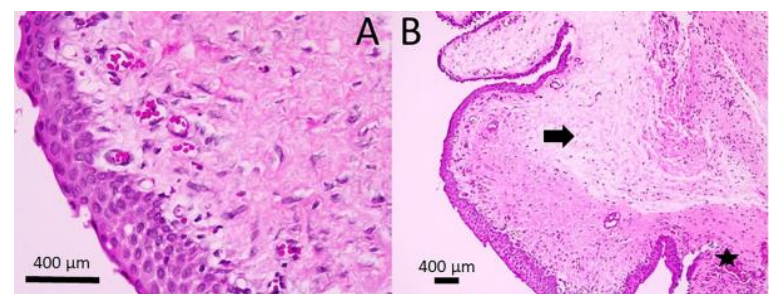

Figura 3 - (A) Presença de estroma conjuntivo normal revestido por epitélio conjuntival sem células caliciformes em detalhe. (B). Em aumento menor observa-se discreto edema (seta) do estroma conjuntival e leve congestão vascular (estrela), com raras células inflamatórias.

\section{CONCLUSÃO}

A condição conhecida como pseudopterígio ou crescimento aberrante de conjuntiva é incomum em coelhos, com maior prevalência em raças anãs. De acordo com as características do tecido e conceitos oftalmológicos, o termo pseudopterígio pode ser empregado, apesar das evidentes diferenças da condição em seres humanos.

O tratamento de eleição para o pseudopterígio em coelhos é cirúrgico, mas há preocupação com recidivas. A secção radial da membrana em três porções e a sutura do tecido remanescente na conjuntiva bulbar é uma técnica rápida e eficiente para correção do pseudopterígio e, associada ao uso tópico de ciclosporina, previne o crescimento recidivante.

Conclui-se que a técnica aqui apresentada é efetiva para tratamento do pseudopterígio em coelhos, proporcionando ao paciente conforto e qualidade visual.

\section{REFERENCIAS}

ALLGOEWER, I.; MALHO, P.; SCHULZE, $H$. et al. Aberrant conjunctival stricture and overgrowth in the rabbit. Veterinary Ophthalmology, v.11, p.18-22, 2008.

ARNBJERG, J. Pseudopterygium in a pygmy rabbit. Veterinary Medicine / Small Animal Clinician, v.74, p.737738, 1979.

FISHER, P.G.; LACKNER, P.A.; DONNELY, T.M. Epicorneal membrane on the eye of a Rex rabbit. Laboratory Animals, v.31, p.23-5, 2002.

HOLMBERG, B.J. Ophthalmology of exotic pets. In: Maggs, D.J; Miller, P.E.; Ofri, R. Slatter's fundamentals of veterinary ophthalmology, 4.ed. Missouri: Saunders Elsevier, 2008, Cap.20, p.427-441.

KATSUTA, O.; SHINOMIYA, K.; MOCHIZUKI, T. et al. Pseudopterygium: Unique conjunctival stricture observed in Japanese white rabbit. Journal of Toxicologic Pathology, v.21, p.239241, 2008.

KIM, J.Y.; WILLIAMS, D.L.; RHO, K. et al. Surgical correction of aberrant conjunctival overgrowth in a rabbit: a case report. Irish Veterinary Journal, 66:18, 2013.

LIBERGE, P.; DESCOTES, J.; JONSSON, M. et al. Pseudopterygium during a one year rabbit intraocular toxicity study. Journal of Toxicology: Cutaneous and Ocular Toxicology, v.18, p.273, 1999.

ROZE, M. Epicorneal conjunctival membrane: Trial of treatment with 
topical cyclosporine. Pratique Médicale

et Chirurgicale de L'Animal de

Compagnie, v.37, p.153-156, 2002.

ROZE, M.; RIDINGS, B.; LAGADIC, M. Comparative morphology of epicorneal conjunctival membranes in rabbits and human pterygium.

Veterinary

Ophthalmology, v.4, p.171-174, 2001.

SCHOOFS, S.; HANSSEN, P.H. EPICORNEAL conjunctival membrane in the rabbit: A clinical case and surgical therapy. Vlaams Diergeneeskundig Tijdschrift, v.67. p.344-346, 1998

TURNER, S.M. Aberrant conjunctival overgrowth in rabbits. In: Nind, F. Small animal ophthalmology. Saunders Solutions in Veterinary Practice: London: Saunders Elsevier, 2008, Cap.14, p.8588.

WILLIAMS, D.L. The rabbit eye. In Williams, D.L. Ophthalmology of Exotic Pets. 1.ed. lowa: WileyBlackwell, 2012, p.15-55. 